\title{
Research on a Steel Built-Up Beam with Varying Corrugated Webs
}

\author{
Dheeraj Tahiliani1 $^{1}$, Anuj Meena ${ }^{1}$, Dhruv Narola', Apurva Dave ${ }^{1}$ \\ ${ }^{1}$ Pandit Deendayal Petroleum University \\ Gandhinagar, Gujarat, India. \\ Dheeraj.tcv15@sot.pdpu.ac.in; Anuj.mcv15@sot.pdpu.ac.in; Dhruv.ncv15@sot.pdpu.ac.in; \\ apurva.dave@sot.pdpu.ac.in
}

\begin{abstract}
Corrugated steel plate are used extensively in field of steel structure. Form past few decades it is widely been used as corrugated web of girder. The objective of this research is to check the performance of corrugated web steel built-up beam in terms of applied load and resulting displacement by experimental test. Three different types of corrugated web profiles are erected with same material properties. These erected corrugated web steel built up beams are tested with load application (point load) and conditions. The resulting performance of each beam is recorded and compared. The experimental results gave unique information, which indicates the role of various parameters in performance of corrugated web steel built up beam.
\end{abstract}

Keywords: Beam, Corrugated web, stress, strain, vertical deflection, different supporting conditions.

\section{Introduction}

The basic element of all buildings and structures is usually a frame structure consisting of beams. In order to reduce the consumption of steel in manufacturing such a structure perforated and corrugated [1-8] constructions have been invented. Steel beams with corrugated web are now actively used in buildings and structures of different application [3, 5, and 8]. Beams are often used as critical support trusses or the main framework in buildings. Steel beams ensure a structure's integrity with relentless strength and support [9]. The immense power of corrugated beams reduces the need to include numerous support structures, saving time and money, as well as making the structure more stable. The versatility and dependability of these beams make them a coveted resource to every builder.

That is why experimental research of steel beams with corrugated web under concentrated static point load has recently been carried out in the laboratory of Pandit Deendayal Petroleum University.

\section{Materials and methods}

\subsection{Material}

The primary functions of the web plate in a plate girder is to maintain the relative distance between the top and bottom flanges and to resist the introduced shearing force. For the use in most practical ranges of span lengths a plate girder is designed. Here we have prepared 3 types of beams based on the shape of the web viz. Trapezoidal (A), Triangular (B) and Rectangular $(\mathrm{C})$. The materials used are flat rolled with dimensions and specifications in table 1. Here we have used galvanized iron-hot rolled sheets. The beam was prepared for specified dimensions of flange and web, and welded with the help of resistance spot welding with current of 50A.

Table 1: Test Specimen Dimensions.

\begin{tabular}{|l|c|}
\hline Thickness of Flange & $1 \mathrm{~mm}$ \\
\hline Thickness of Web & $0.2 \mathrm{~mm}$ \\
\hline Width of Flange & $75 \mathrm{~mm}$ \\
\hline
\end{tabular}




\begin{tabular}{|c|c|c|c|c|c|c|}
\hline Profile & $\begin{array}{c}\text { Length of } \\
\text { flange }(\mathbf{m m})\end{array}$ & $\begin{array}{c}\text { Length of } \\
\text { web }(\mathbf{m m})\end{array}$ & $\mathbf{A}(\mathbf{m m})$ & B (mm) & C (mm) & D (mm) \\
\hline Trapezoidal & 880 & 930 & 35 & 115 & 70 & 60 \\
\hline Triangular & 880 & 920 & 35 & 120 & 115 & - \\
\hline Rectangular & 880 & 1160 & 35 & 115 & - & - \\
\hline
\end{tabular}

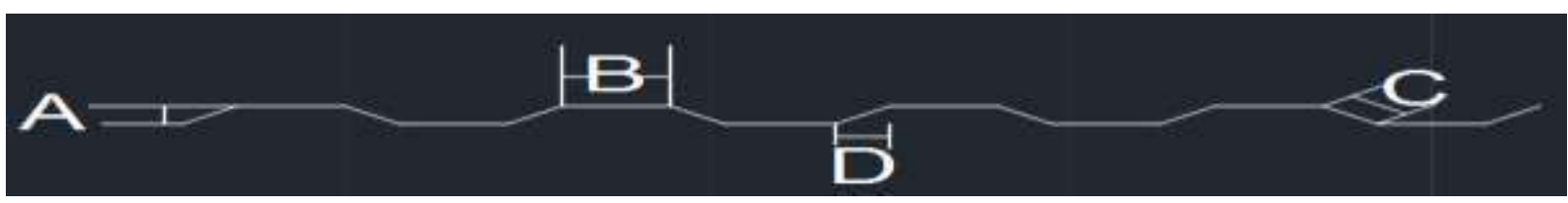

(1)

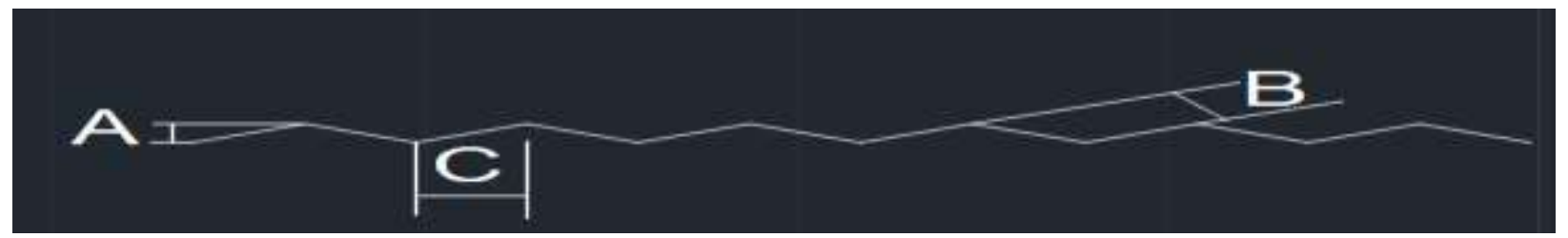

(2)

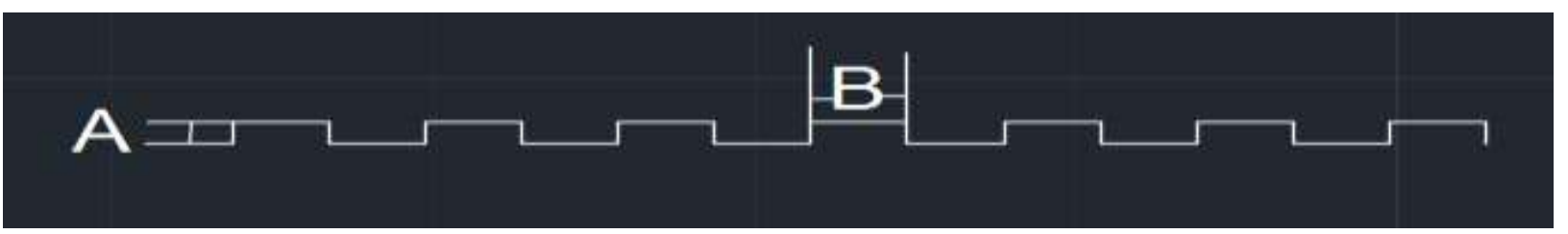

(3)

Fig. 1-3: Dimension detailing of specimen.

\subsection{Test setup}

This test set up is designed for testing deflection at various distance and also along both horizontal and vertical axis, machine that is capable of testing the deflection for various samples of different specimen from metals. Using method of erecting truss this test set up has been prepared. All parts are welded in multiple layers so that the rig is rigid and undistorted under the action of loading. A test rig was designed and commissioned as the base support for the test specimens and in providing the three-point bending condition. Also the beams to be tested can be supported on required supporting conditions such as both end fixed, both ends hinged or one end hinged and one end fixed. The test setup is such that the test can be performed on a range of specimens varying in length, height and thickness with minor adjustments in the setup. Moreover it was also observed that the beams failed along with the occurrence of lateral torsional buckling (Figure 7) hence the beams were supported with end stiffeners on both ends made up of material used for flange.

The arrangements for measurement of horizontal deflection: Two dial gauges at L/4 distance from support A, two dial gauges at the center near the one-point loading, two dial gauges at L/4 distance from support B.(figure4). For measurement of vertical deflection one dial gauge is placed at the center of the beam below the one-point load and at the bottom of the beam. 


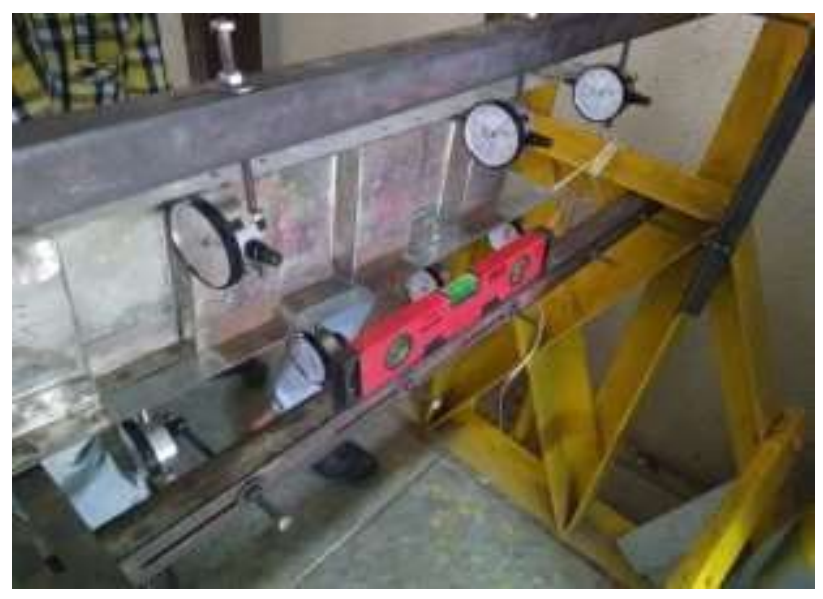

Fig. 4: Specimen in test setup.

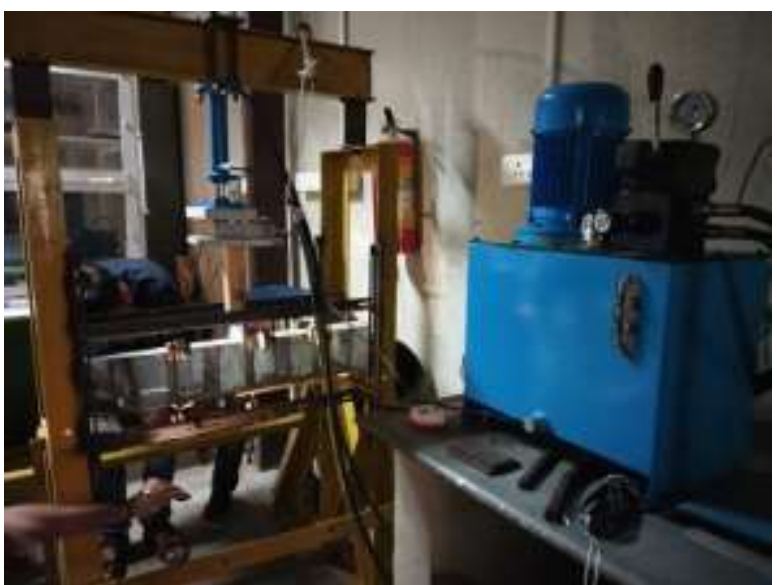

Fig. 5: Entire test setup.

\section{Results}

Table 2: Rectangular beam deflection results.

\begin{tabular}{|c|c|c|c|c|c|c|c|}
\hline $\operatorname{Load}(\mathbf{N})$ & $1(\mathrm{~mm})$ & $2(\mathrm{~mm})$ & $3(\mathrm{~mm})$ & $4(\mathrm{~mm})$ & $5(\mathrm{~mm})$ & $6(\mathrm{~mm})$ & $7(\mathrm{~mm})$ \\
\hline $0 * 9.81=0$ & 0 & 0 & 0 & 0 & 0 & 2.87 & 0 \\
\hline 49.05 & 0.34 & 0 & 0 & 0 & 0.71 & 2.17 & 0.2 \\
\hline 98.1 & 0.67 & 0 & 0 & 0 & 0.72 & 2.35 & 0.6 \\
\hline 147.15 & 0.75 & 0 & 0 & 0 & 0.74 & 1.95 & 1.1 \\
\hline 196.2 & 1.87 & 0 & 0 & 0 & 2.05 & 1.53 & 1.7 \\
\hline 245.25 & 2.06 & 0 & 0 & 0 & 2.11 & 1.01 & 2.1 \\
\hline 294.3 & 2.45 & 0 & 0 & 0 & 2.37 & 0.78 & 2.8 \\
\hline 343.35 & 3.4 & 0 & 0 & 1.8 & 3.12 & 0 & 3.2 \\
\hline 392.3 & 4.1 & 0 & 0 & 3.15 & 3.77 & 0 & 3.7 \\
\hline 441.45 & 4.97 & 0 & 0 & 3.16 & 4.67 & 0 & 4.3 \\
\hline \multicolumn{2}{|c|}{ Profile } & $\begin{array}{c}\text { Length of } \\
\text { web } \\
(\mathrm{mm})\end{array}$ & $\begin{array}{c}\text { Angle of } \\
\text { inclination } \\
\left(\alpha^{0}\right)\end{array}$ & $\begin{array}{l}\text { Load carrying } \\
\text { capacity } \\
(\mathrm{N}) \\
\end{array}$ & \multicolumn{2}{|c|}{$\begin{array}{c}\text { Deflection at } \\
\text { Centre } \\
(\mathrm{mm}) \\
\end{array}$} & $\begin{array}{c}\text { Def. at } 220 \mathrm{~mm} \\
\text { both sides from } \\
\text { center }(\mathrm{mm})\end{array}$ \\
\hline \multicolumn{2}{|c|}{ Rectangular } & 1160 & 90 & 441.45 & \multicolumn{2}{|c|}{4.6} & 3.16 \\
\hline \multicolumn{2}{|c|}{ Triangular } & 920 & 16.60 & 353.16 & \multicolumn{2}{|c|}{4.1} & 2.8 \\
\hline \multicolumn{2}{|c|}{ Trapezoidal } & 930 & 35 & 382.59 & \multicolumn{2}{|c|}{3.85} & 2.5 \\
\hline
\end{tabular}

On comparison it is found that the load carrying capacity of Rectangular web increases by $15.3 \%$ with respect to Trapezoidal web, similarly the trapezoidal has $8.3 \%$ higher strength compared to Triangular Web profile. Also the pattern for variation of deflection at center appears nearly to be the same. Since the properties of all the profiles are kept same, the variations in the profile were observed to understand the pattern of this variation.

The major variations in the profile of these webs are running length of web, Angle of inclination different bids of spot welding. The conclusions discussed among the authors and the few ruling possibilities of such variation in strength as well as in deflection in the steel built-up beams are explained in Conclusions (4.). 
The test setup was arranged and mantled so as to obtain the highest form of accuracy but there are some points and places such as resistance spot welding, moulding of web profile, arrangement of specimen in test setup, and reading of dial gauge etc. where some glitches may have been generated.

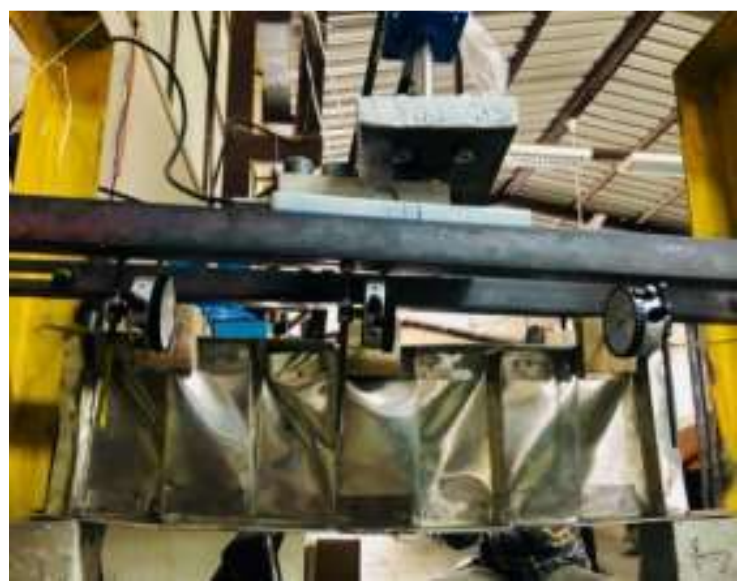

Fig. 6: Specimen after deflection.

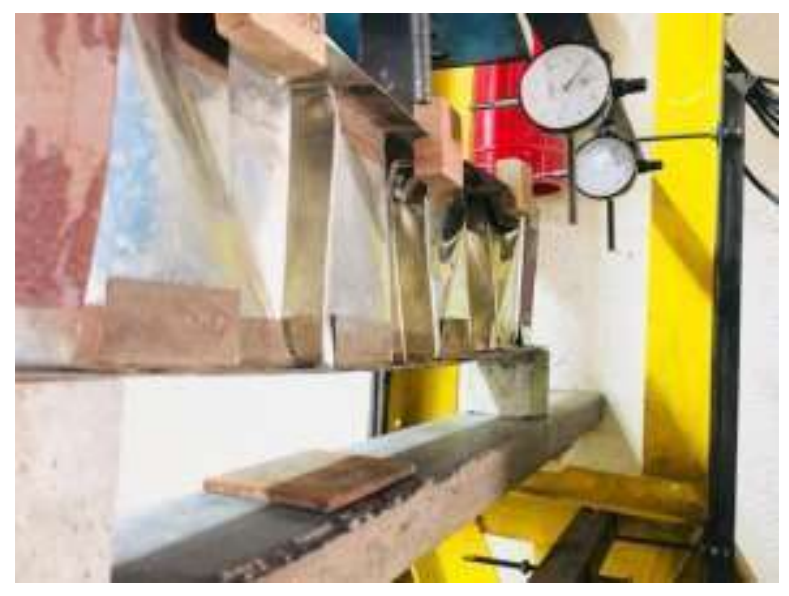

Fig. 7: Torsional buckling of specimen.

\section{Conclusion}

Lateral torsional buckling may occur in an unrestrained beam. A beam is considered to be unrestrained when its compression flange is free to displace laterally and rotate. When an applied load causes both lateral displacement and twisting of a member lateral torsional buckling has occurred. Figure 8 shows the lateral displacement and twisting experienced by a beam when lateral torsional buckling occurs.

Moreover on comparison it is also found that the element having more length of web showed higher strength properties compared to the reamaining profiles. Hence rectangular beam proved to more strong for the same dimensions of all the beams. The reason for this is due to more amount of material used in sheet of web which in increases the contact of web with flange(both upper and lower)

Also the results can be compared by considering the angle of inclination, i.e the angle of profile with the base of web profie(along the length of beam). Through this it can be concluded that the profile having higher angle of inclination has possibility of showing more strength carrying capacity.

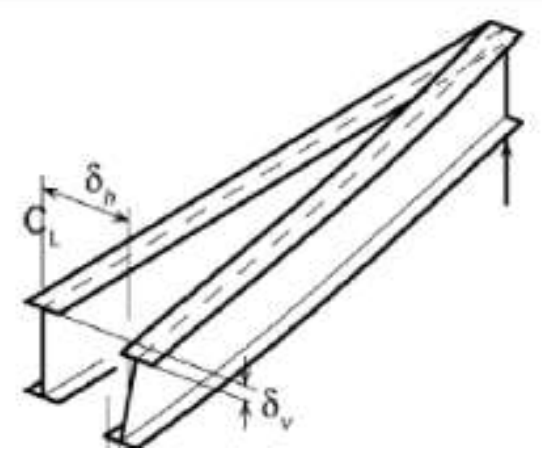

Fig. 8: Lateral Torsional Buckling. 


\section{References}

[1] R. Luo, B. Edlund, "Analyzed the strength of the hot-rolled steel plate girders with trapezoidal corrugated webs in shear or under patch loading," Nordic Steel Construction conference, 1995.

[2] R. Luo, B. Edlund, "Studied the shear capacity of hot-rolled steel plate girders with trapezoidal corrugated webs numerically using a non-linear finite element method," Journal of Thin-Walled Structures, 1996.

[3] Sung C. Lee and Chai H. Yoo, "Studied the behavior of girders with corrugated webs up to failure using non-linear element analysis," Journal of Structural Engineering, ASCE, 1998.

[4] C. L. Chan, Y. A. Khalid, B. B. Sahar, A. M. S. Hamouda, "Finite element analysis of corrugated web beams under bending," Journal of Constructional Steel Research, 2002.

[5] Y. A. Khalid , C. L. Chan, B. B. Sahari, A. M. S. Hamouda, "Bending behavior of corrugated web beams," Ph.D. dissertation, Department of Mechanical and Manufacturing Engineering, University Putra Malaysia, 2003-04.

[6] E. Y. Sayed-Ahmed, "Lateral torsion buckling behaviour of hot-rolled steel I-girders with plain and corrugated webs," in Proceedings Of The Institution Of Civil Engineers, Structures And Buildings, 2005.

[7] H. H. Abbas, R. Sause, R. G. Driver, "Behavior of corrugated webs I-girders under in plane loading," J. Eng. Mech, ASCE, 2006.

[8] Mutasim E. Ibrahim, "Behavior of hot-rolled steel plate girders with trapezoidal corrugated webs under fatigue loading," International Journal for Research in Applied Science \& Engineering Technology, 2006.

[9] A. Limaye and P. M. Alandkar, "Strength of welded Plate Girder with Corrugated Web Plate," International Journal of Engineering Research and Applications, vol. 3, pp. 1925-1930, 2013. 